Thorax (1975), 30, 91.

\title{
Serial measurement of plasma cortisol in lung cancer
}

\author{
I VAN LICHTER and NANCY E. SIRETT \\ Department of Surgery and NZMRC Endocrinology Research Unit, \\ University of Otago Medical School, Dunedin, New Zealand
}

\begin{abstract}
Lichter, I. and Sirett, Nancy E. (1975). Thorax, 30, 91-94. Serial measurement of plasma cortisol in lung cancer. Serial plasma cortisol estimations were carried out in 81 male lung cancer patients and in a control group of 50 male subjects with conditions other than lung cancer. It was found that group mean plasma cortisol levels, both in the morning and in the afternoon, were greater in the lung cancer patients than in the nocancer control group. However, long-term assessment four years after the beginning of the study showed that high plasma cortisol levels were found predominantly in cancer patients within six months of death. If such patients are excluded from the study, there is no significant difference in group mean plasma cortisol levels between male lung cancer patients and a male control group.
\end{abstract}

There have been several reports indicating that plasma cortisol levels in patients with lung cancer are higher than those in control groups.

Segaloff, Hatch, and Rongone (1962) found that plasma corticoid levels in 26 patients with lung cancer were generally higher than in six control patients who had benign lung lesions and in six normal male controls. A similar study was conducted by Hatch, Segaloff, and Ochsner (1965), who investigated 100 patients with lung cancer and considered that 71 had elevated plasma corticoid levels. Borkowski et al. (1969) observed increased plasma and/or urinary 17hydroxycorticosteroids in $20 \%$ of 76 lung cancer patients. Kawai et al. (1969) found that only nine of 23 lung cancer patients showed normal values in adrenocortical function tests.

Lichter and Sirett (1968) confirmed that in lung cancer patients, the group mean plasma cortisol levels, both in the morning and in the afternoon, were greater than in control subjects. Although the mean group differences between the two groups were significant, the range of individual values within the lung cancer group and the nolung-cancer group was so wide that the test could not be used diagnostically.

This study (Lichter and Sirett, 1968) was continued, and patients were followed up over a fouryear period, repeat plasma cortisol estimations being carried out at intervals to assess the relation- ship of the plasma cortisol level to the stage of the disease.

\section{PATIENTS AND METHODS}

The investigation of plasma cortisol levels in lung cancer patients was continued for four years, after which results were reviewed. The patients and methods used were those described in an earlier communication (Lichter and Sirett, 1968).

A control group of 66 patients comprising 50 men and 16 women was studied. Morning and afternoon plasma specimens were taken from each patient. There appeared to be a tendency for higher cortisol levels to be recorded among the small group of women in this series. To exclude any possible effect this might have on the results in the lung cancer group and the control group, only male patients were subjected to analysis.

Eighty-one male lung cancer patients were included in the study. Morning and afternoon plasma cortisol levels were performed on each patient. During the period under study 68 patients died. Plasma cortisol levels of the lung cancer group as a whole were compared with those taken from patients within six months of their death and with patients within three months of death.

\section{RESULTS}

The plasma cortisol levels of the controls and of the three groups studied are given in the Table and in Figure 1. 
T A B L E

MORNING AND AFTERNOON PLASMA CORTISOL LEVELS IN CONTROL SUBJECTS, IN THE WHOLE GROUP OF MALE LUNG CANCER PATIENTS, IN THOSE PATIENTS WITHIN 6 MONTHS OF DEATH, AND IN THOSE WITHIN 3 MONTHS OF DEATH

\begin{tabular}{|c|c|c|c|c|c|}
\hline & \multirow{3}{*}{ No. } & \multicolumn{4}{|c|}{ Plasma Cortisol $(\mu \mathrm{g} / 100 \mathrm{ml})$} \\
\hline & & \multicolumn{2}{|c|}{$8.30 \mathrm{am}$} & \multicolumn{2}{|c|}{$4.30 \mathrm{pm}$} \\
\hline & & $\underset{\text { SEM }}{\text { Mean }} \pm$ & SD & $\underset{\text { SEM }}{\operatorname{Mean}} \pm$ & SD \\
\hline $\begin{array}{l}\text { Male controls } \\
\text { All male lung cancer patients } \\
\text { Male lung cancer patients } \\
\text { within } 6 \text { months of death } \\
\text { within } 3 \text { months of death }\end{array}$ & $\begin{array}{l}50 \\
81 \\
40 \\
26\end{array}$ & $\begin{array}{l}18 \cdot 1 \pm 0 \cdot 8 \\
22 \cdot 5 \pm 0.8 \\
24 \cdot 9 \pm 0.9 \\
26 \cdot 7 \pm 1 \cdot 6\end{array}$ & $\begin{array}{l}5 \cdot 3 \\
7 \cdot 1 \\
5 \cdot 9 \\
8 \cdot 3\end{array}$ & $\begin{array}{l}14 \cdot 6 \pm 0 \cdot 7 \\
17 \cdot 5 \pm 0 \cdot 8 \\
20 \cdot 0 \pm 0 \cdot 8 \\
22 \cdot 2 \pm 1 \cdot 6\end{array}$ & $\begin{array}{l}5 \cdot 1 \\
6 \cdot 8 \\
4 \cdot 9 \\
8 \cdot 0\end{array}$ \\
\hline
\end{tabular}

SEM = standard error of the mean.

SD = standard deviation.

$\begin{array}{cccc}\text { Controls } & \text { All male lung } & \text { Male lung cancer } & \text { Male lung concer } \\ n=50 & \text { cancer patients } & \text { patients within } 6 & \text { potients within } 3 \\ n-81 & \text { months of death } & \text { months of death } \\ n=40 & & n=26\end{array}$

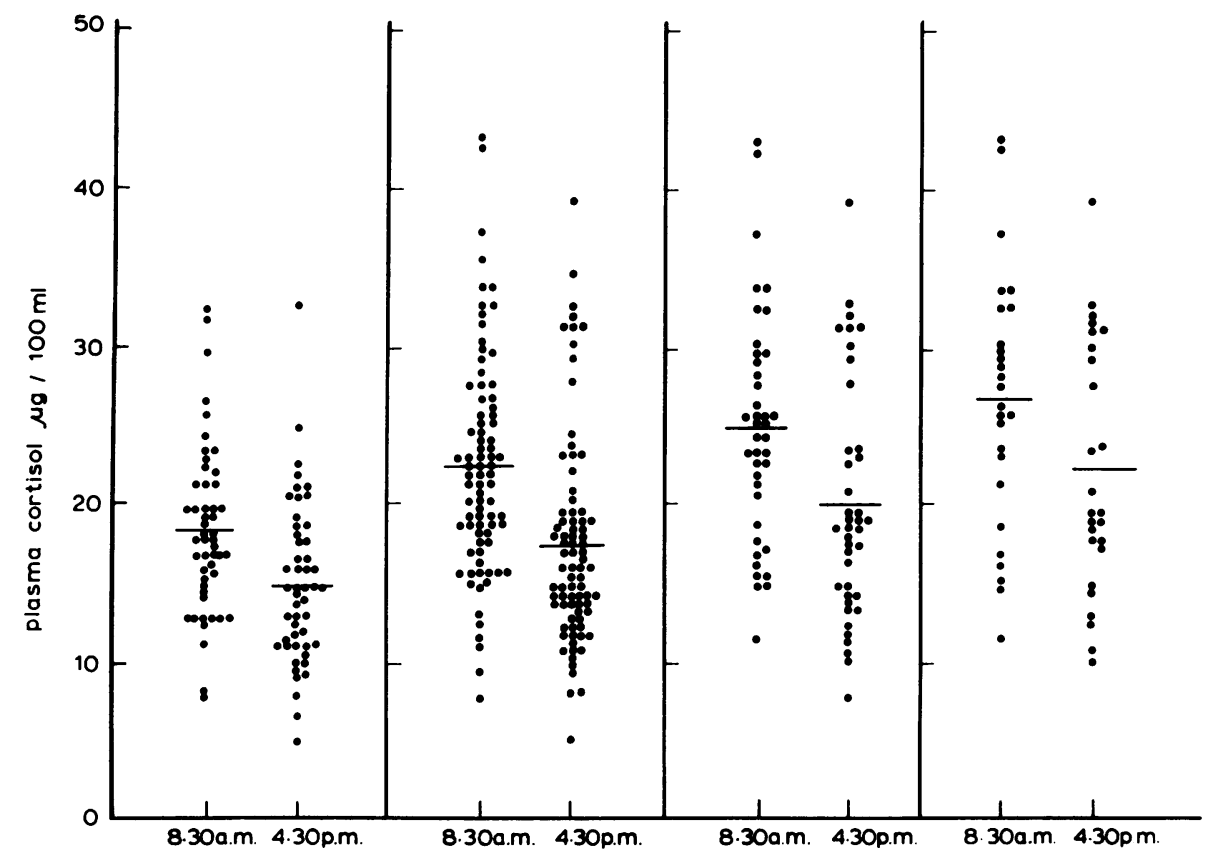

FIG. 1. Distribution of morning and afternoon plasma cortisol levels in male control subjects, in the whole group of male lung cancer patients, in those within six months of death, and in those within three months of death.

Among the 81 male lung cancer patients, the morning cortisol levels showed a highly statistically significant elevation as compared with male controls $(0.1 \%$ level of statistical significance). The afternoon levels were significant at the $5 \%$ level. If patients within three months of death $(26$ patients) are excluded from the analysis, there is a reduction to the $5 \%$ level of significance in the morning cortisol levels; the afternoon levels no longer show a significant difference between lung cancer patients and controls. If patients within six months of death are excluded (a further 14 patients, so excluding in all 40), the morning and afternoon levels show no significant difference between controls and lung cancer patients among the 41 patients remaining in the study (Fig. 2). 


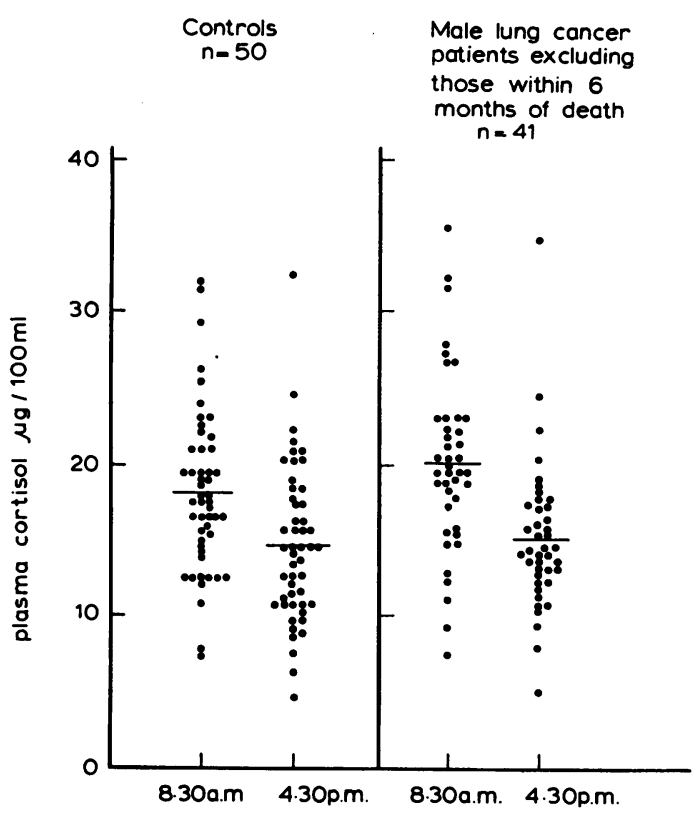

FIG. 2. Distribution of morning and afternoon plasma cortisol levels in male control subjects and in male lung cancer patients excluding those within six months of death.

There was no significant correlation between cell type and plasma cortisol levels in 81 male cancer patients.

\section{DISCUSSION}

These findings indicate that the elevated plasma cortisol levels found in previous studies in groups of lung cancer patients depend on having within those groups patients within six months of death. If such patients are excluded from the study, there is no significant difference in group mean plasma cortisol levels between male lung cancer patients and a male control group.

The report of Werk and Sholiton (1960) supports these conclusions. Of 22 patients with lung cancer in whom increased morning plasma 17hydroxycorticoid levels were demonstrated, 18 had secondary deposits and some were very ill. Rao and Hewit (1970) showed that several values of steroid excretion correlated significantly with the survival time in patients with inoperable lung cancer.

These findings are in keeping with the observation that patients dying of lung cancer show an increase in the width of the adrenal cortex
(Sholiton, Incze, and Werk, 1961; Caranasos and Ruebner, 1963). Segaloff et al. (1962) considered that this was not due to the prolonged stress of the disease, as patients with non-malignant pulmonary lesions showed no evidence of adrenocorticol hyperactivity. However, Sandberg et al. (1956) stated that raised plasma corticoid levels could be expected in patients dying from a variety of illnesses.

The plasma cortisol measurements recorded show that high levels are found predominantly in lung cancer patients within six months of death, and that raised levels are particularly likely to be found among those within three months of death. The afternoon plasma cortisol level is a more critical discriminant than the morning level. However, high levels occasionally occur in control subjects, and there is even some overlap in individual values within the terminal lung cancer group and the control group.

Our thanks are due to Miss J. Hardman, Department of Preventive and Social Medicine, for the computer analysis of the results; to the Medical Illustration Department for the figures; and to the Medical Photographic Department for the reproductions.

\section{REFERENCES}

Borkowski, A., Levin, S., Mahler, A., and Verhas, V. (1969). A study of adrenal function in 76 consecutive cases of bronchial carcinoma. European Journal of Cancer, 2, 263.

Caranasos, G. and Ruebner, B. H. (1963). Adrenal width and metastasis in bronchogenic carcinoma. Archives of Pathology, 76, 263.

Hatch, H. B. Jr., Segaloff, A., and Ochsner, A. (1965). Adrenocortical function in bronchogenic carcinoma: Study of 100 patients. Annals of Surgery, 161, 645.

Kawai, A., Tamura, M., Tanimoto, S., Honma, H., and Kzuya, N. (1969). Studies on adrenal cortical function in patients with lung cancer. Metabolism, 18, 609.

Lichter, I. and Sirett, N. E. (1968). Plasma cortisol levels in lung cancer. British Medical Journal, 2, 154.

Rao, L. G. S. and Hewit, M. L. (1970). Prognostic significance of a steroid-discriminant function in patients with inoperable lung cancer. Lancet, 2 , 1063.

Sandberg, A. A., Eik-Nes, K., Migeon, C. J., and Samuels, L. T. (1956). Metabolism of adrenal steroids in dying patients. Journal of Clinical Endocrinology and Metabolism, 16, 1001. 
Segaloff, A., Hatch, H. B., and Rongone, E. L. (1962). Elevated plasma corticoids associated with lung cancer. Cancer Chemotherapy Reports, 16, 343.

Sholiton, L. J., Incze, J. S., and Werk, E. E. Jr. (1961). Adrenocortical width in carcinoma of the lung. Cancer, 14, 105.

Werk, E. E. Jr. and Sholiton, L. J. (1960). Adreno- cortical function in carcinoma of the lung. Cancer, 13, 469.

Requests for reprints to: Professor Ivan Lichter, F.R.C.S., Department of Surgery, University of Otago \& Medical School, Dunedin, New Zealand. 